\title{
Cav2.2-mediated signaling in the neural circuits underlying anxiety
}

\author{
Ying Zhou ${ }^{1}$ Kimie Niimi ${ }^{2}$, Weidong $\mathrm{Li}^{1}$ and Eiki Takahashi' ${ }^{* 1,2}$ \\ ${ }^{1}$ Bio-X Institutes, Key Laboratory for the Genetics of Developmental and Neuropsychiatric Disorders (Ministry of Education), Shanghai Jiao Tong University, \\ Shanghai, 200240, People's Republic of China \\ ${ }^{2}$ Research Resources Center, RIKEN Brain Science Institute, Saitama, 351-0198, Japan
}

\begin{abstract}
Neuronal voltage-gated Cav2.2 channels mediate the presynaptic machinery responsible for the release of neurotransmitters. In our previous studies, mice that received intracerebroventricular injections of $\omega$-conotoxin GVIA, a Cav2.2 blocker, exhibited decreased baseline levels of dopamine and serotonin within the striatum and frontal cortex, deficits that resulted in depressive behaviors. However, the role of Cav2.2 in neural circuits underlying anxiety remains poorly understood. In the present study, intracerebroventricular injection of $\omega$-conotoxin GVIA ( $5 \mathrm{pg} / \mathrm{side})$ in mice resulted in behavioral deficits in the elevated plus maze, light-dark exploration, and marble burying tests. These results indicate that inhibition of Cav2.2-mediated signaling induces alterations in the neuronal network involved in anxiety-related behaviors.
\end{abstract}

\section{Introduction}

At the presynaptic terminal, two major voltage-gated $\mathrm{Ca}^{2+}$ channel types, Cav2.1 (P/Q-type) and Cav2.2 (N-type), are critically involved in the $\mathrm{Ca}^{2+}$-dependent exocytotic release of neurotransmitters [1]. $\mathrm{Ca}^{2+}$ influx via these channels triggers neurotransmitter release in cooperation with other components of the vesicle fusion machinery $[2,3]$. Given the pivotal role of $\mathrm{Ca}^{2+}$ channels in controlling neurotransmitter release, defects in the expression, localization, structure, or modulation of presynaptic $\mathrm{Ca}^{2+}$ channels may result in aberrant synaptic signaling leading to various patterns of neural network dysfunction. Cav2.2 channels reportedly influence the release of dopamine [4-6], serotonin [7], glutamate [8], gamma-aminobutyric acid [GABA]; [9], acetylcholine [10], and norepinephrine [11] from central neurons.

Anxiety disorders (panic disorder/agoraphobia, generalized anxiety disorder, social phobia, and specific phobias) are the most common mental illnesses. Anxiety disorders are most likely caused by a combination of biological, psychological, and environmental factors. Most individuals with these disorders appear to have a biological vulnerability to stress, making them more susceptible to environmental stimuli than the rest of the population. Studies suggest that an imbalance among certain neurotransmitters contributes to anxiety disorders $[12,13]$. The neurotransmitters targeted in anxiety disorders are dopamine, serotonin, and GABA. Serotonin appears to be particularly important in feelings of well-being, and deficiencies are highly related to anxiety and depression $[12,13]$. Thus, because the precise regulation of neurotransmitter release via Cav2.2 channels plays an important role in the functioning of neuronal circuits, alterations in Cav2.2-mediated signaling induces anxiety and depressive disorders.

In previous studies, mice that received intracerebroventricular (i.c.v.) injections of $\omega$-conotoxin GVIA, a Cav2.2 blocker, exhibited decreased baseline levels of dopamine and serotonin within the striatum and frontal cortex [14] and showed deficits in depressive behavioral tests [15]. However, the role of Cav2.2 in neural circuits underlying anxiety remains poorly understood. Anxious behavior is assessed using the elevated plus maze [16], light-dark exploration [17], and marble burying [18] behavioral tests.

In the present study, to investigate the relationship between Cav2.2-mediated signaling and anxious behavior, mice administered i.c.v. $\omega$-conotoxin GVIA were assessed using the elevated plus maze, light-dark exploration, and marble burying behavioral tests.

\section{Materials and methods}

\section{Mice}

All animal procedures were approved by the Animal Experiments Committee of Shanghai Jiao Tong University and RIKEN. C57BL/6J mice were provided by Charles River Japan (Kanagawa, Japan). The mice were given free access to water and food pellets (CRF-1; Oriental Yeast Co. Ltd., Tokyo, Japan) and housed under a 12/12-h light/dark cycle (lights on from 08:00 to 20:00) at $23 \pm 1^{\circ} \mathrm{C}$ and $55 \pm 5 \%$ humidity. We used separate groups of 2-month-old male mice for each of the behavioral tests. All experiments were conducted during the light phase by investigators blinded to the treatment conditions.

Correspondence to: Eiki Takahashi, Research Resources Center, RIKEN Brain Science Institute 2-1 Hirosawa, Wako, Saitama, 351-0198, Japan, Tel: +81-48467-5871; Fax: +81-48-467-9692; E-mail: etakahashi@brain.riken.jp

Key words: anxiety, Cav2.2, elevated plus maze test, light-dark exploration test, marble-burying test, $\omega$-Conotoxin GVIA

Received: December 10, 2015; Accepted: December 24, 2015; Published: December 28, 2015 


\section{Infusions}

For the infusion studies, the Cav2.2 blocker $\omega$-conotoxin GVIA $(100 \mathrm{pg} / \mu \mathrm{L}$, Peptide Institute, Osaka, Japan) was dissolved in saline (vehicle). The drug dose was determined based on a previous report $[15,19,20]$. Control mice received an equivalent volume of vehicle. Under anesthesia and using standard stereotaxic procedures, stainlesssteel guide cannulae (22-gauge) were implanted into the lateral ventricle (posterior to bregma, $-0.34 \mathrm{~mm}$; lateral to the midline, $\pm 0.9 \mathrm{~mm}$; ventral from the dura, $-2.3 \mathrm{~mm}$ ), and mice were allowed to recover for at least 1 week following surgery. The mice were briefly anesthetized with isoflurane to facilitate insertion of the injection cannula (26-gauge). Infusion into the lateral ventricle $(0.1 \mu \mathrm{L} /$ side $)$ was accomplished at a rate of $0.05 \mu \mathrm{L} / \mathrm{min} 30 \mathrm{~min}$ before behavioral testing. The injection cannula was left in place for $2 \mathrm{~min}$ following infusion.

\section{Elevated plus maze test}

The apparatus consisted of two open arms $(\mathrm{L} \times \mathrm{W}: 30 \times 5 \mathrm{~cm})$ and two closed arms $(\mathrm{L} \times \mathrm{W} \times \mathrm{H}: 30 \times 5 \times 15 \mathrm{~cm})$ that extended from a common central platform $(\mathrm{L} \times \mathrm{W}: 5 \times 5 \mathrm{~cm})$. A small raised lip $(0.3$ $\mathrm{cm}$ ) around the perimeter of the open arms prevented the mice from falling. The apparatus was made of Plexiglas ${ }^{\circ}$, with a gray floor and walls, and was elevated $45 \mathrm{~cm}$ above floor level. At the beginning of each experiment, a mouse was placed on one of the open arms with its head directed toward the central platform. The mice were allowed to explore the apparatus freely under 20-lux illumination for $10 \mathrm{~min}$. Behavior was recorded using an overhead video camera. Arm entry was defined as all four legs entering into one of the arms. The number of transitions between the arms, the number of entries into the open arms, and the time spent in the open arms were measured.

\section{Light-dark exploration test}

The apparatus consisted of two compartments: a dark compartment $(\mathrm{L} \times \mathrm{W} \times \mathrm{H}: 15 \times 10 \times 20 \mathrm{~cm})$ and a light compartment $(\mathrm{L} \times \mathrm{W} \times \mathrm{H}$ : $20 \times 15 \times 20 \mathrm{~cm})$. The dark compartment had a lid on top and was made of black Plexiglas ${ }^{\circ}$, whereas the light compartment was open at the top and was made of white Plexiglas ${ }^{\oplus}$. A black Plexiglas ${ }^{\oplus}$ tunnel (L $\times \mathrm{W} \times \mathrm{H}: 10 \times 7 \times 4.5 \mathrm{~cm}$ ) separated the dark box from the light box. The light intensity in the experimental room was 100 lux. A mouse was placed in the dark compartment, and its behavior was recorded on videotape over a $10-\min$ period. The number of transitions between the compartments and the time spent in the light compartment were measured. A mouse with all four paws in the light compartment was considered to be fully within the light compartment.

\section{Marble burying test}

Mice were individually placed in transparent polycarbonate cages $(\mathrm{L} \times \mathrm{W} \times \mathrm{H}: 30 \times 30 \times 30 \mathrm{~cm})$ containing a 5 -cm layer of sawdust and 25 glass marbles $(2.5 \mathrm{~cm}$ in diameter $)$ evenly spaced against the walls of the cage. A mouse was placed in the cage, and marble-burying behavior was recorded using a video camera for $20 \mathrm{~min}$. The light intensity in the experimental room was 50 lux. The number of marbles that were buried at least two-thirds in sawdust and the time spent exhibiting marble-burying behavior were evaluated.

\section{Statistical analysis of the behavioral results}

The data are presented as the means \pm standard error of the mean (SEM). Statistical analyses were conducted using Excel Statistics 2006 (SSRI, Tokyo, Japan). The data were analyzed using analysis of variance. Tukey's test was performed when appropriate. The results

were considered significant at a $5 \%$ or lower probability of error.

\section{Results}

The present study examined the effects of i.c.v. injections of $\omega$-conotoxin GVIA on anxious behaviors. Two groups of male mice ( $n$ $=10$ each) were administered i.c.v. injections of either vehicle or $10 \mathrm{pg} /$ side $\omega$-conotoxin GVIA for each test.

In the elevated plus maze (Figure 1), the total number of arm entries did not differ significantly between vehicle-injected and $\omega$-conotoxin GVIA-injected mice. The number of open arm entries differed significantly between vehicle-injected and $\omega$-conotoxin GVIAinjected mice; the number of open arm entries was significantly less for $\omega$-conotoxin GVIA-injected mice compared with vehicle-injected mice.

In the light-dark exploration test (Figure 2), the number of transitions between the light and dark boxes did not differ significantly between vehicle-injected and $\omega$-conotoxin GVIA-injected mice. The time spent in the light box differed significantly between vehicleinjected and $\omega$-conotoxin GVIA-injected mice; the $\omega$-conotoxin GVIA-injected mice spent significantly less time in the light box compared with vehicle-injected mice.

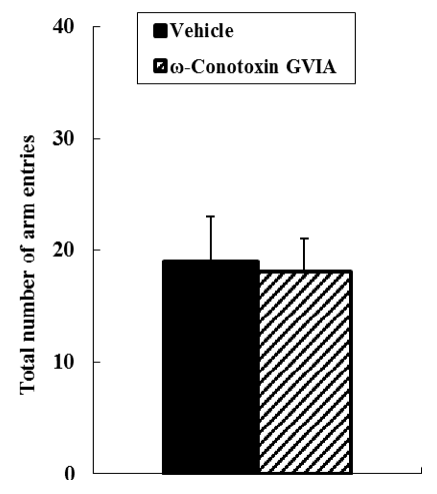

C

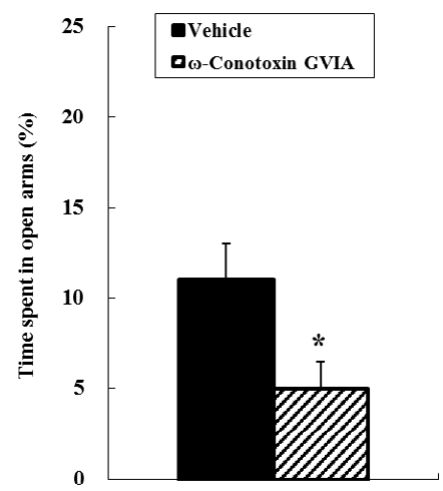

Figure 1. Elevated plus maze. The vehicle- or $\omega$-conotoxin GVIA-injected mice wer allowed to explore the maze freely for $10 \mathrm{~min}$. The total number of entries was counted (A). The number of entries into the open arms is expressed as a percentage of the total number of arm entries (B). The time spent in the open arms is expressed as a percentage of the total arm entry time (C). The data are presented as means \pm standard error of the mean (SEM). $* P<0.05$ compared with the appropriate control. 


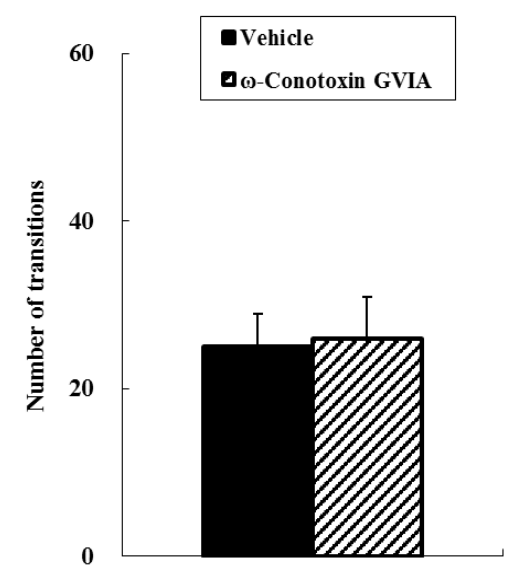

B

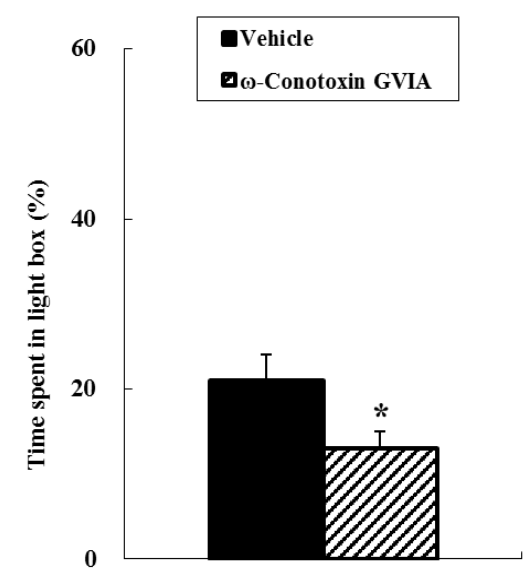

Figure 2. Light-dark exploration. Vehicle-injected or $\omega$-conotoxin GVIA-injected mice were placed in the dark box for a 10-min period. The number of transitions between boxes was measured (A). The time spent in the light compartment is expressed as a percentage of the total time in the light and dark compartments (B). The data are presented as means \pm SEM. $* P<0.05$ compared with the appropriate control.

In the marble burying test (Figure 3), the number of marbles buried by $\omega$-conotoxin GVIA-injected mice was greater than that buried by vehicle-injected mice. A significant induction in the duration of marble-burying behavior was observed in $\omega$-conotoxin GVIA-injected mice compared with vehicle-injected mice.

\section{Discussion}

Neuronal Cav2.2 channels are expressed predominantly at presynaptic neuronal terminals throughout the central nervous system and mediate neurotransmitter release [1-3]. In our previous study, mice that received i.c.v. injections of the Cav2.2 blocker, $\omega$-conotoxin GVIA, exhibited decreased baseline levels of dopamine and serotonin within the striatum and frontal cortex [14]. The neurotransmission of monoamines is thought to control emotional behavior [6-11,2124]. Although emotional behavior may also be mediated by other neurotransmitter systems, decreased levels of dopamine and serotonin might be at least partly responsible for the emotional behaviors. Indeed, $\omega$-conotoxin GVIA-injected mice showed aberrations in the neuronal network affecting depressive mechanisms [15]. These reports suggest that Cav2.2 channel dysfunction and subsequent changes in dopamine and serotonin release are at least partly responsible for changes in depressive behavior. However, the role of Cav2.2 channels in the neural circuits underlying anxiety has not been examined. In the present study, we investigated the relationship between Cav2.2mediated signaling and anxious behaviors in mice that received i.c.v. injection of $\omega$-conotoxin GVIA using the elevated plus maze, lightdark exploration, and marble burying behavioral tests.

In the elevated plus maze test, $\omega$-conotoxin GVIA-injected mice spent significantly less time in the open arms compared with vehicleinjected mice. In addition, a higher degree of anxiety was apparent in $\omega$-conotoxin GVIA-injected mice in both the light-dark exploration and marble burying tests. Our results imply that $\omega$-conotoxin GVIA-

A

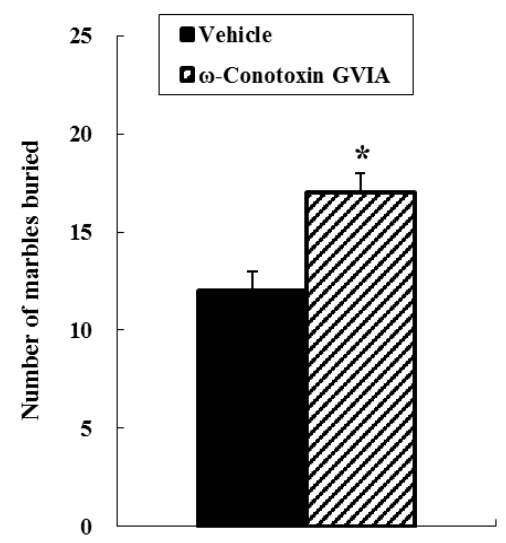

B

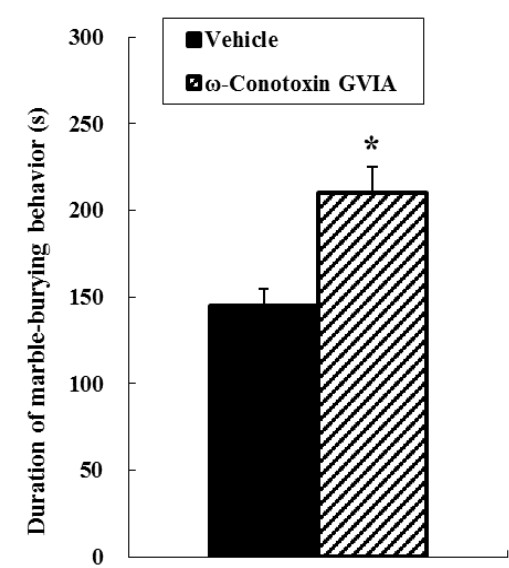

Figure 3. Marble burying behavioral test. Vehicle-injected or $\omega$-conotoxin GVIA-injected mice were placed in the apparatus, and marble-burying behavior was measured over a 20 -min period. The number of marbles buried was counted (A). The duration of marbleburying behavior is shown (B). The data are presented as means \pm SEM. ${ }^{*} P<0.05$ compared with the appropriate control. 
injected mice show increased anxiety levels, and that abnormalities in Cav2.2-mediated neuronal circuits contribute to the basic pathophysiological mechanisms underlying anxious behaviors. To further examine how Cav2.2 channel-dependent signaling influences anxiety-related behaviors, electrophysiological studies and neurotransmitter release analyses will be required.

Cav2.2 channel knockout mice exhibited normal activity during the light phase and became more active during the dark phase [25]. In our previous study, open field test analyses revealed no significant differences in motor activity between vehicle-injected and $\omega$-conotoxin GVIA-injected mice [15]. In the present study, the total number of arm entries did not differ significantly between $\omega$-conotoxin GVIA- and vehicle-injected mice in the elevated plus maze test. In the light-dark exploration test, the number of transitions between the light and dark boxes did not differ significantly between the two groups of mice. These results indicate that Cav2.2 channel-dependent signaling has no influence on spontaneous activity, at least during the light phase.

In the present study, we showed that the inhibition of Cav2.2mediated signaling by the specific Cav2.2 blocker $\omega$-conotoxin GVIA induced anxiety-related behavioral deficits in mice in the elevated plus maze, light-dark exploration, and marble burying behavioral tests. Previous findings indicated the presence of significant relationships between Cav2.2-mediated signaling and the dopaminergic and serotonergic systems [14] and between Cav2.2-mediated signaling and the expression of depression-related behavior [15]. These findings suggest that inhibition of Cav2.2-mediated signaling induces emotional changes due to alterations in the neuronal circuit system associated with Cav2.2 dysfunctions.

\section{Acknowledgments}

This work was supported by China 973 project (2010CB529604) and National Scientific Foundation of China (81271511 and 30900432).

\section{Conflicts of interest}

The authors declare no competing interests.

\section{Authors' contributions}

WL and ET designed and supervised the research, and wrote the manuscript. YZ and KN performed the surgeries and behavioral experiments. All authors read and approved the final version of the manuscript.

\section{References}

1. Yokoyama CT, Myers SJ, Fu J, Mockus SM, Scheuer T, et al. (2005) Mechanism of SNARE protein binding and regulation of Cav2 channels by phosphorylation of the synaptic protein interaction site. Mol Cell Neurosci 28: 1-17. [Crossref]

2. Catterall WA (1998) Structure and function of neuronal $\mathrm{Ca}^{2+}$ channels and their role in neurotransmitter release. Cell Calcium 24: 307-323. [Crossref]

3. Berridge MJ, Lipp P, Bootman MD (2000) The versatility and universality of calcium signalling. Nat Rev Mol Cell Biol 1: 11-21. [Crossref]

4. Herdon H, Nahorski SR (1989) Investigations of the roles of dihydropyridine and omega conotoxin-sensitive calcium channels in mediating depolarization-evoked endogenous dopamine release from striatal slices. Naunyn Schmiedebergs Arch Pharmacol 340: 36-40. [Crossref]

5. Turner TJ, Adams ME, Dunlap K (1993) Multiple $\mathrm{Ca}^{2+}$ channel types coexist to regulate synaptosomal neurotransmitter release. Proc Natl Acad Sci U S A 90: 9518-9522. [Crossref]
6. Woodward JJ, Rezazadeh SM, Leslie SW (1988) Differential sensitivity of synaptosomal calcium entry and endogenous dopamine release to omega conotoxin. Brain Res 475: 141-145. [Crossref]

7. Foehring RC (1996) Serotonin modulates N- and P-type calcium currents in neocortical pyramidal neurons via a membrane-delimited pathway. J Neurophysiol 75: 648-659. [Crossref]

8. Luebke JI, Dunlap K, Turner TJ (1993) Multiple calcium channel types control glutamatergic synaptic transmission in the hippocampus. Neuron 11: 895-902. [Crossref]

9. Horne AL, Kemp JA (1991) The effect of omega-conotoxin GVIA on synaptic transmission within the nucleus accumbens and hippocampus of the rat in vitro. $\mathrm{Br} J$ Pharmacol 103: 1733-1739. [Crossref]

10. Wessler I, Dooley DJ, Werhand J, Schlemmer F (1990) Differential effects of calcium channel antagonists (omega-conotoxin GVIA, nifedipine, verapamil) on the electrically-evoked release of $[3 \mathrm{H}]$ acetylcholine from the myenteric plexus, phrenic nerve and neocortex of rats. Naunyn Schmiedebergs Arch Pharmacol 341: 288-294. [Crossref]

11. Dooley DJ, Lupp A, Hertting G, Osswald H (1988) Omega-conotoxin GVIA and pharmacological modulation of hippocampal noradrenaline release. Eur J Pharmacol 148: 261-267. [Crossref]

12. Reinhold JA, Rickels K (2015) Pharmacological treatment for generalized anxiety disorder in adults: an update. Expert Opin Pharmacother 16: 1669-1681. [Crossref]

13. Asan E, Steinke M, Lesch KP (2013) Serotonergic innervation of the amygdala: targets, receptors, and implications for stress and anxiety. Histochem Cell Biol 139: 785-813. [Crossref]

14. Zhou Y, Niimi K, Li W, Takahashi E (2015) Inhibition of Cav2.2-mediated signaling induces sensorimotor gating deficits. Integr Mol Med 2: 256-260.

15. Zhou Y, Niimi K, Li W, Takahashi E (2015) Role of Cav2.2-mediated signaling in depressive behaviors. Integr Mol Med 2: 369-372.

16. Pellow S, Chopin P, File SE, Briley M (1985) Validation of open:closed arm entries in an elevated plus-maze as a measure of anxiety in the rat. $J$ Neurosci Methods 14: 149-167. [Crossref]

17. Crawley JN (1981) Neuropharmacologic specificity of a simple animal model for the behavioral actions of benzodiazepines. Pharmacol Biochem Behav 15: 695-699. [Crossref]

18. Ichimaru Y, Egawa T, Sawa A (1995) 5-HT1A-receptor subtype mediates the effect of fluvoxamine, a selective serotonin reuptake inhibitor, on marble-burying behavior in mice. Jpn J Pharmacol 68: 65-70. [Crossref]

19. Zhou Y, Niimi K, Li W, Takahashi E (2015) Disruption of spatial cognition by intraaccumbens injection of Cav2.2 inhibitor. Integr Mol Med 2: 109-111.

20. Zhou Y, Niimi K, Li W, Takahashi E (2015) Spatial short-term memory regulated by Cav2.2-mediated NMDA receptor signaling. Integr Mol Med 2: 131-134.

21. Rodgers RJ, Nikulina EM, Cole JC (1994) Dopamine D1 and D2 receptor ligands modulate the behaviour of mice in the elevated plus-maze. Pharmacol Biochem Behav 49: 985-995. [Crossref]

22. Zhou QY, Palmiter RD (1995) Dopamine-deficient mice are severely hypoactive, adipsic, and aphagic. Cell 83: 1197-1209. [Crossref]

23. Gainetdinov RR, Wetsel WC, Jones SR, Levin ED, Jaber M, et al. (1999) Role of serotonin in the paradoxical calming effect of psychostimulants on hyperactivity. Science 283: 397-401. [Crossref]

24. Zhuang X, Gross C, Santarelli L, Compan V, Trillat AC, et al. (1999) Altered emotiona states in knockout mice lacking 5-HT1A or 5-HT1B receptors. Neuropsychopharmacol 21: 52S-60S. [Crossref]

25. Nakagawasai O, Onogi H, Mitazaki S, Sato A, Watanabe K, et al. (2010) Behavioral and neurochemical characterization of mice deficient in the N-type $\mathrm{Ca}^{2+}$ channel alpha1B subunit. Behav Brain Res 208: 224-230. [Crossref]

Copyright: (C2015 Zhou Y. This is an open-access article distributed under the terms of the Creative Commons Attribution License, which permits unrestricted use, distribution, and reproduction in any medium, provided the original author and source are credited. 